\title{
Designer Requirements for Visual Capability Loss Simulator Tools: Differences between Design Disciplines
}

\author{
Katie Cornish, Joy Goodman-Deane and P. John Clarkson \\ University of Cambridge, Department of Engineering, Cambridge, United Kingdom \\ $\{$ klc49, jag76, pjc10\}@cam.ac.uk
}

\begin{abstract}
There is a low uptake of inclusive design tools in industry, partly due to a poor fit between design tools and the thought and work processes of designers. Simulating visual capability losses is a technique with great potential in helping designers improve inclusivity and accessibility. However, we need to understand the needs of designers from different disciplines to improve the fit of these tools and their uptake in industry.

This study aims to determine designers' needs for vision loss simulators, and how this varies between disciplines. Interviews were carried out with 15 designers from five disciplines. The results suggest that one tool is not suitable for all. The graphic and web designers interviewed required a tool to aid communication with clients, however, the industrial and engineering designers required two tools, depending on the stage of the design process. To increase their uptake, simulator tools should be used in education.
\end{abstract}

Keywords: Design Tools, Inclusive Design, Simulation, Vision Impairment, Design Discipline.

\section{Introduction}

Inclusive design is an "approach to designing in which the designers ensure that their products and services address the needs of the widest possible audience, irrespective of age or ability" [1]. The ageing population is making inclusive design more important than ever. The Disability Discrimination Act [2] and the Americans with Disabilities Act [3] also add legal drivers. Its successful implementation can provide businesses with access to a wider market, and increased customer satisfaction [4]. Despite this, products that are inclusively designed are still rare [5].

One explanation for a lack of inclusively designed products is the low uptake of inclusive design in industry $[6,7]$. This is, in part, because the tools, methods and materials required for inclusive design are not being fully utilized [8]. The utilization of these tools could be encouraged by improving the fit between them, and the way in which designers think and work $[6,7]$.

The simulation of the loss of visual capabilities is an effective technique that is liked by designers [9]. Losses in visual capability are particularly important to consider as the likelihood of developing a visual impairment increases with age [10]. Vision

adfa, p. 1, 2011.

(C) Springer-Verlag Berlin Heidelberg 2011 
simulation can take the form of a software tool where a design is uploaded and the effect of a visual impairment is applied to it on screen. It can also take the form of a wearable tool such as a set of glasses which the designer wears to replicate the effects of a visual impairment. By generating empathy, vision simulation increases designers' understanding of their users [11]. This assists in the creation of more accessible products, services and built environments. The technique is particularly important as designers are often young and healthy [12] making it difficult for them to understand those with reduced capabilities [13].

As previously mentioned, the utilization of these tools could be encouraged by improving the fit between them, and the way in which designers think and work [6, 7]. Designers from different disciplines work in different ways and so it is important to identify how their requirements for a simulator tool differ. By adopting a usercentered process we can increase our understanding of designers' needs [14].

This paper details a study involving interviews with practicing designers from different disciplines, with the aim of improving the fit between vision loss simulators and designers' thought and work processes.

\section{Previous Work}

\subsection{Existing Visual Capability Loss Simulator Tools}

Vision simulation for designers has been used in industry by Ford, IDEO, Interval Research Corporation, and Siemens and Bosch Home Appliances [15 - 18].

Formal simulation tools include software tools such as the Inclusive Design Toolkit's Simulation Software [4] and the VisionSim App [19]. They also include wearable tools such as the Cambridge Simulation Glasses [4] and the Fork in the Road SimSpecs [20]. Informal techniques include smearing Vaseline on glasses to blur the wearer's vision [21].

Research that evaluates existing vision loss simulators with regard to the needs of designers is limited. Dong et al. [14] evaluated a range of tools including the Cambridge Simulation Glasses and the Inclusive Design Simulation Software. She identified a number of designer requirements not currently met by the tools. Cardoso [22] also identified designer requirements for a simulator tools. However, he concluded that the simulator tools he evaluated "required further revision in order to be effectively and efficiently utilized". This highlights the need for more work in this area.

\subsection{Design Disciplines}

Design practice encompasses a spectrum of disciplines, but vision loss simulators are created for 'designers' in general. Lawson [23] recognizes this spectrum of design as ranging from art to science. He suggests that an engineer works in a "precise, systematic and mechanical" way whereas a fashion designer is more "imaginative, unpredictable and spontaneous". Although this may be an overly simplistic view of the complex differences between design disciplines, it highlights that different disciplines may have different requirements from a tool. 
In addition to this it is widely reported that we need to increase our understanding of design practice and create design tools in a user-centered way [6], [14], [23, 24]. Therefore we should investigate the needs of designers from different disciplines in a user-centered way, to create tools that have a better fit with their individual thought and work processes.

\subsection{Barriers and Drivers for Inclusive Design}

There is limited research on what makes a successful vision loss simulator. However, some lessons can be learnt from research focusing more generally on the barriers and drivers for inclusive design. These include the designer's individual preferences, the company, client, design process, and design discipline [6]. Barriers include concerns that tools may limit a designer's creativity and impact on the aesthetics of the finished product, as well as client barriers [26]. Recommendations for successful tools include making them quick and easy to use, flexible, stimulating, concise, inspiring, usable and useful [14], [27]. However, we may need to be cautious in applying these general findings to vision loss simulators.

\section{Method}

\subsection{Aim}

The aim of this study is to understand whether one visual capability loss simulator tool is suitable for all designers, and how tool requirements vary between design disciplines on the art-to-science spectrum.

\subsection{Sample}

The participants consisted of 15 practicing designers, three from each of the following disciplines: graphic design, web design, industrial design, architecture and engineering design. These design disciplines were selected based on the most common disciplines listed in designer directories and design school courses throughout the world. They represent a range of disciplines on the art-to-science spectrum, and create products, buildings or services that need to be visually accessible. This will allow us to investigate the differences between designers from different disciplines.

\subsection{Data Collection and Analysis}

Designers were contacted by e-mail using design directories [28 - 30] and personal contacts. They confirmed which discipline they felt they belonged to prior to their interview, and the aim of the study was explained to them. All designers were located in Cambridge or London, except one who was based in the US. They were offered no incentives to take part. 
Each designer took part in a semi-structured interview lasting between 30 minutes and an hour. These were carried out in the participant's chosen location (except for the designer in the US where Skype was used). The interviews covered the following topics: background questions on the designer's current job and education relevant to it; their current consideration of visual accessibility; and their use of tools for both visual accessibility and in other areas of design. The designers were then given an explanation of the Cambridge Simulation Glasses and how they work with the opportunity to try them out. They were asked about their opinion of the tool, their likelihood of using it and an explanation for this. They were also asked how the tool might be improved to suit them, and whether they would use other tools, such as a softwarebased vision loss simulator.

All designers were asked to complete a consent form before taking part. The interviews were recorded on a digital audio recorder and with hand-written notes, and transcribed and analyzed using QSR NVivo 8 software [31]. This was in accordance with a general inductive approach for qualitative data analysis [32] where data are reduced to identify the main themes. One interview was double coded by an independent researcher, which facilitated an in-depth discussion about the themes and their definitions. This led to the refinement, re-organization and clarification of the themes, and the inclusion of previously missing themes. The full data set was recoded where necessary in accordance with the new themes. This helped to ensure the reliability of the coding.

\section{$4 \quad$ Results}

The results of the 15 interviews are presented in the following section, grouped according to the five design disciplines: graphic design, web design, industrial design, architecture and engineering design. A participant number has been included where direct quotes have been used. For example G1, G2 and G3 have been used for the three graphic designers, and W1, W2 and W3 for the three web designers.

\subsection{Graphic Design}

The graphic designers considered visual accessibility to be important in their discipline. However, they felt that some graphic designers do not currently carry out tests to ensure their designs are visually accessible. One participant added that "a designer that is not doing some legibility tests, to me, is not a good designer" (G1) suggesting that there is a 'best practice' but there might be a divide within the discipline.

The participants added that visual accessibility is particularly important in graphic design because "everything is visual" (G1). They suggested that testing visual accessibility should be a requirement of all projects and that if they had access to the Cambridge Simulation Glasses they would use them. This suggests that considering visual accessibility could be less project-dependant in graphic design than in other disciplines, and therefore a vision loss simulator would be most useful to them. 
Graphic designers currently use informal methods to test their designs. These include removing their glasses, asking the opinions of colleagues, using Photoshop to blur designs, and printing small versions of their designs. However, they agreed that a formal tool such as a vision loss simulator would be useful.

The graphic designers emphasized the importance of the client when considering visual accessibility. For example the client may have a really developed brief. Alternatively, they may have "a tiny understanding about what they want" (G1). This requires the designer to spend a lot of time trying to understand the client's needs, but it does allow for a discussion about visual accessibility. They added that a vision loss simulator would be beneficial in aiding this discussion, but emphasized the importance of being able to calculate population exclusion. For example, if they could tell their client that " $20 \%$ of the potential customers can't read that sort of series two font, then they'd take notice" (G2).

The graphic designers felt that both a wearable tool and a software tool would be useful in their industry. However, there were concerns that when using the tool a designer would use it "for the first couple of months, and then put it away and like forget about it" (G3). Therefore the tool would have to be easily accessible and embedded in the design process.

Finally, the graphic designers were in agreement that including vision loss simulators in education would improve their uptake in industry. One graphic designer stated that "to be able to see a simulator tool in university would make you think about it all the time, and understand how it actually works" (G3) making her more likely to consider using it in the future.

\subsection{Web Design}

There was a higher level of recognition of the importance of visual accessibility amongst the web designers, in comparison with the graphic designers. It was suggested that this was due to the existence of guidelines and standards in the industry such as the W3C Web Content Accessibility Guidelines [33]. One designer added that using them has "become so natural and common sense" (W1).

There is still a variety in the level of understanding amongst clients, with one web designer reporting that "normally in the brief that you get from a public facing organization, such as a university or a charity, they will stipulate what level of accessibility they want their website to be at" (W3) which demonstrates the high level of awareness of some clients. However, another web designer regularly has to convince his clients of the importance of visual accessibility, and often the client doesn't agree. This results in the designer adapting his design to meet the client's requirements by "biting their tongues and making the changes" (W2), often making it less accessible. He added that the client sometimes returns at a later date, asking for it to be more visually accessible, and the designer reverts to his original ideas. They suggested that a vision loss simulator could help them convince clients of the importance of visual accessibility. 
Web designers were also slightly more in favor of a wearable tool. One graphic designer stated that the Cambridge Simulation Glasses would be really useful as "you could actually show them to a client in a meeting... getting people involved and sharing that experience so everyone understands is much better than an isolated plug in for me... it's the group awareness and the group knowledge especially from the client's perspective because as designers we're aware of this anyway" (W3). This demonstrates their preference for a wearable tool over a software tool as it allows better communication with the client. Another web designer was worried about the complexities of a software-based tool, with the third web designer being happy to use either type.

Again, there was a clear acknowledgement of the importance of education in promoting designer's awareness of inclusive design and the tools and methods available. One web designer stated that "when people in education are actually using these sorts of tools, it will invariably filter down into industry" (W3).

\subsection{Industrial Design}

The industrial designers gave a mixture of responses with regard to whether visual accessibility is considered. This may be due to the larger diversity of products created. For example, the designer working in medical device design, suggested that designers in the area have to consider visual accessibility as it is required by the legislation. He added that "in development (of a medical device) you'd have to prove that you tested it”' (I2) for visual accessibility. However, he suggested that this may be less important in areas that are not subject to such strict legislation.

Their likelihood of using a tool also varied depending on the structure and focus of the company. For example one designer worked in a company with a dedicated human factors team, and felt it was the job of this team to ensure visual accessibility, rather than his. However, he added that the Cambridge Simulation Glasses would be useful within the company.

Again, it was noted that there are different types of client. Those clients wanting a medical device seem to accept the need for visual accessibility tests, as this is a factor covered by the legislation. However, those who want a consumer product are less likely to recognize the importance of visual accessibility. One designer added that "probably one of the key benefits, of the Cambridge Simulation Glasses, is at the start of a lot of projects you have a workshop with the client, and that's basically where you explore the problem space... with the client. So you get them to think about all the stuff that they're not doing at the moment. So a nice little exercise could be if everyone wore these glasses, and they realized how the extreme user isn't experiencing it like they thought they would" (I2). This process would be really useful in communicating with clients who didn't already recognize the need for visual accessibility.

One industrial designer took this further, suggesting the need for two tools with different aims depending on the stage of the design process. The first tool would be for use early in the design process to generate empathy and encourage the understanding of clients and other stakeholders. "We do workshops with clients where we get 
them, with their stakeholders, involved... empathy tools in those scenarios are quite good" (I1). The designer added that a tool for use with a client needs to appear reliable and robust so as not to undermine the designer's competence.

The second tool would be used to calculate population exclusion (and validate a product against industry legislation where needed) later in the design process. This tool would also need to "cover several different conditions... color blindness, some sort of occlusion, cataracts... I would absolutely $100 \%$ use this" (I3). This would be much more complex and data driven, based on large amounts of population data, but would only be used by designers. Participants felt that this would be more useful than an empathy tool later in the design process and when validating highly regulated and safety critical products.

Again, the importance of education in promoting the use of vision loss simulators was highlighted. One industrial designer recounted: "my first experience with empathy tools came in my third year of university with simulator goggles... it was the first real empathy tool I ever used, and it sort of stuck with me. If I ever did a project where I had to design to be inclusive I'd definitely use it" (I2). He suggested that in addition using them in education they could be promoted through industry social media, magazines and conferences.

\subsection{Architecture}

The architects reported that a simulator tool would be of very little use to their industry due to the design process that they typically use. They felt that a wearable vision loss simulator could potentially be used at the end of the process to test designs. However, the designs are often one-offs without large-scale prototypes so cannot be tested early on. Furthermore, if a flaw was found with a building after it had been completed they are unlikely to go back and change it. The architects did state that "elements within a building such as pre-manufactured pod bathrooms" (A1) could be tested using the glasses before multiple copies were made.

A software-based simulator tool could potentially be beneficial, but only on larger projects such as the design of an airport terminal. Smaller architectural firms are less likely to create a 3D computer design of the building before it is built and so a software tool would be of no use to them. "We are not creating a $3 D$ space as such... I suspect some firms are moving on towards actually creating the $3 D$ model of the building... but because we haven't got that $3 D$ model there's nothing really at this point that a plug in would give to us" (A3).

Furthermore, budgeting for a "final stage check" with the glasses would be difficult as budgets often get used up on other unforeseen areas, leaving little or no money at the end. One architect explained that often during the design process "there have been a lot of... unexpected things that come up, and put pressure on the budget... it would be tough to hold money back until that point for those kind of activities and not have it get used up by other unforeseen things" (A2). 


\subsection{Engineering Design}

The engineering designers were similar to the industrial designers in a number of ways. They also gave mixed responses with regard to whether visual accessibility is considered. Again, this could be due to the large diversity of products created.

Furthermore, they also suggested that a number of different tools may be needed depending on the stage of the design process. One engineer stated that "I think it depends on what stage in the process you're actually working at, I think if you're very early concept a quick look see is brilliant, you don't need it to be calibrated"(E1). He added that a later stage test would have to be much more rigorous as "with any test approach you have to validate your test protocol to be confident that your results are any good". This would need to take into account factors such as different visual impairments and lighting levels and work with industry standards and legislation.

Similarly to the industrial designers, the company structure in engineering design also impacts on the designer's likelihood of using a visual loss simulator. One engineer working in a company with a particular focus on usability felt that it was important that all members of the company (including engineers, human factors specialists, graphic designers, marketing, clients and managers) had as much knowledge about the user as possible. He felt that although this gave them a competitive advantage. However, he felt that this company's ethos was in the minority, albeit in the context of a growing trend.

Another engineer outsources all human factors work stating that "we are a small company with 10 people... we have got a huge range of expertise in house but we can't do everything" (E2). Although he added that a simple visual loss simulator would be interesting to use and have around the office. These examples highlight the need for different types of tool depending on the stage of the design process.

\section{Discussion}

The aim of this study was to understand whether one visual capability loss simulator tool is suitable for all designers, and how tool requirements vary between design disciplines on the art-to-science spectrum. A comparison across the disciplines demonstrates that one tool is not suitable for all designers as they have different requirements depending on their discipline.

\subsection{Comparison Across Disciplines}

A comparison of the results across the disciplines highlighted the main themes with regard to requirements for vision loss simulators.

Firstly, most designers questioned recognised the importance of visual accessibility in their discipline (whether they currently tested for it or not). The majority of designers suggested that a vision loss simulator would be useful in their discipline, and that if they had access to a set of the Cambridge Simulation Glasses they would probably 
use them. The exception to this rule was the architects who didn't feel that a vision loss simulator would be useful to them.

Secondly, the architects would not use the tool because of the design process that they follow. They suggested that it is difficult for them to budget for final stage checks and so a wearable tool would not be useful. Furthermore they often do not create a full 3D model of each project, so they wouldn't be able to use a software tool.

Thirdly, it was clear across all disciplines (again with the exception of architecture) that the client has a large impact on whether visual accessibility is considered. There appears to be a variety in the level of understanding of the importance of visual accessibility amongst clients.

Therefore, a simulator tool to help designers discuss the importance of visual accessibility with their clients would be useful. This would be particularly useful in graphic and web design as these disciplines rely so heavily on vision. The vision loss simulator would need to be formal and generate empathy as well as allowing the calculation of population exclusion data. There was also a slight preference for a wearable tool as it can be used in workshops with clients.

However, industrial and engineering designers would be more likely to require two tools depending on the stage of the design process. Similarly to the graphic and web designers, they would like an empathy tool for use early on in the design process. This would be particularly useful in less regulated areas or where the client doesn't already acknowledge the need for visual accessibility. However, they were also interested in a more complex tool for use solely by designers that validated products against industry standards and legislation. This would need to be more rigorous and reliable and for use later in the design process.

Finally, most designers suggested that including a vision loss simulator in education would improve its uptake in industry. Some added that they should also be featured in industry blogs, magazines, conferences and journals.

\subsection{Limitations of the Study}

It is important to note that as only three designers were interviewed from each discipline the generalizability of the findings to the rest of the discipline is limited. Furthermore, only five disciplines were studied and therefore these results are specific to them. It is also important to recognize that sub-specialisms within each discipline may affect tool requirements. However, this is the first part in a larger project focusing on the improvement of vision loss simulators and provides a solid foundation for future work.

\section{Conclusion}

The main conclusion of this study is that one visual capability loss simulator tool is not suitable for all designers as designers' requirements vary depending on their dis- 
cipline. The main requirements for a vision loss simulator (with the exception of the architects) are as follows;

1. The tool must be easily accessible. The designers generally agreed that they would find a vision loss simulator useful and would use it if they had access to one.

2. For graphic and web designers the tool must work well in discussions with clients. The graphic and web designers in particular felt that a vision loss simulator would help the client understand the need for visual accessibility. The tool should be formal, generate empathy and allow the calculation of population exclusion data. It should also be wearable so it can be used in workshops with clients.

3. For industrial and engineering designers there must be two tools depending on the stage of the design process. The first tool is similar to the one required by the graphic and web designers: for use early in the process in discussion with clients. The second tool is for use later in the process to validate products against industry standards.

4. The tool must feature in design education. This will lead to its adoption in industry and can be helped by promoting the tool in industry blogs, magazines, conferences and journals.

\section{The Impact of the Results and Future Work}

This paper highlighted not only that designers from different disciplines require a subtly different vision loss simulator, but the importance of acknowledging the differences between design disciplines. This has a wider impact in the field and should be acknowledged, particularly when improving the fit between inclusive design tools and the way in which designers think and work.

Future work could investigate the development of two tools. One tool could be used at an early stage when communicating with clients. The second tool could be used to validate products later in the design process. Exactly how this is achieved requires further research which should continue to be conducted in a user-centered way.

This paper is part of a larger study that also investigated the requirements that each designer felt would make a vision loss simulator useful to them. The results of this work have not yet been published but highlight factors such as the need for a tool to be quick and easy to use, available and easily accessible, and to allow the calculation of population exclusion data.

Acknowledgement. We would like to thank the EPSRC for funding this work, and Wolfson College Cambridge for their support. 


\section{$8 \quad$ References}

1. The Design Council, http://www.designcouncil.info/ inclusivedesignresource/

2. The Disability Discrimination Act, http://www. legislation. gov.uk/ukpga/1995/50/contents

3. The Americans with Disabilities Act, http://www.ada.gov/

4. Waller, S., Bradley, M., Hosking, I.,Clarkson, P. J.: Making the case for inclusive design. Applied Ergonomics. 1-7, (2013)

5. Bontoft, M., Pullin, G.: What is an inclusive design process? In: Clarkson, P. J., Coleman, R., Keates, S., Lebbon, C.: Inclusive Design: Design for the whole population, pp 250. Springer, London (2003)

6. Goodman-Deane, J., Langdon, P., Clarkson, P. J.: Key influences on the usercentred design process. Journal of Engineering Design. 21, 345-373 (2010)

7. Mieczakowski, A., Langdon, P., Clarkson, P. J.: Investigating designers' and users' cognitive representations of products to assist inclusive interaction design. Universal Access in the Information Society. 1-18 (2012)

8. Cardoso, C., Keates, S., Clarkson, P. J.: Supplementing User Information During the Inclusive Design Process. International Conference of Inclusive Design and Communications. (2005)

9. Keates, S., Clarkson, P. J.: Countering Design Exclusion: an introduction to inclusive design. Springer, London. (2003)

10. Harvey, P. T.: Common Eye Diseases of Elderly People: Identifying and Treating Causes of Vision Loss. Gerontology. 49, 1-11 (2003)

11. Goodman-Deane, J., Langdon, P., Clarkson, P. J., Caldwell, N., Sarhan, A.: Equipping designers by simulating the effects of visual and hearing impairments. Proceedings of the 9th international ACM SIGACCESS Conference on Computers and Accessibility. 241-242 (2007)

12. Zitkus, E., Langdon, P., Clarkson, P. J.: Accessibility Evaluation: Assistive Tools for Design Activity in Product Development. Proceedings of the 1st International Conference on Sustainable Intelligent Manufacturing. (2011)

13. Goodman-Deane, J., Waller, S., Sarhan, A., Caldwell, N., Clarkson, P. J.: Simulation Software: Providing Insight into the Effects of Vision and Hearing Impairments. INCLUDE. (2011)

14. Dong, H., McGinley, C., Nickpour, F., Cifter, A. S.: Designing for designers: Insights into the Knowledge Users of Inclusive Design. Applied Ergonomics. $1-8,(2013)$

15. Hitchcock, D., Taylor, A.: Simulation for Inclusion-true User-Centred Design. Proceedings of International Conference on Inclusive Design. (2003)

16. IDEO's Human-Centred Design Toolkit, http://www.ideo.com /work/human-centered-design-toolkit/

17. Leonard, D., Rayport, J. F.: Spark Innovation Through Empathic Design. Harvard Business Review. 75, 102-115 (1997)

18. Siemens: Cooking Up a Better Life, http://www.siemens.com/ innovation/apps/pof microsite/ pof-fall2010/_html_en/cooking-up-a-betĒer-life.html 
19. Apple Inc. VisionSim by Braille Institute., https://itunes .apple. com/gb/app/visionsim-by-brailleinstitute/id525114829? mt $=8$

20. Fork in the Road Vision Rehabilitation Services http://www . lowvisionsimulators.com/sitecontent/product/full-set

21. Nicolle, C., Maguire, M.: Empathic Modelling in Teaching Design for All. Proceedings of International Conference on Human-Computer Interaction. (2003)

22. Cardoso, C.: Design for Inclusivity: Assessing the Accesibility of Everyday Products. PhD Thesis: University of Cambridge. (2005)

23. Lawson, B.: How Designers Think: The Design Process Demystified $\left(4^{\text {th }}\right.$ Ed.). Architectural Press, Oxford. (2005)

24. Blessing, L., Chakrabarti, A.: DRM, a Design Research Methodology. Springer, London. (2009)

25. Nickpour, F., Dong, H.: Developing User Data Tools: Challenges and Opportunities. Designing Inclusive Interactions. 79-88 (2010)

26. Dong, H., Keates, S., Clarkson, P. J.: Inclusive Design in Industry : Barriers, Drivers and the Business Case. User-Centred Interation Paradigms for Universal Access in the Information Society. 305-319 (2004)

27. Goodman, J., Langdon, P., Clarkson, P. J.: Formats for User Data in Inclusive Design. Universal Access in Human Computer Interaction: Coping with Diversity. 117-126. Springer, Heidelberg. (2007)

28. The Directory of Design Consultants, http://www. designdirectory . co.uk/

29. The Dexigner Directory, http://www.dexigner.com/directory/

30. Designer Listings, http://www. designerlistings .org/

31. QSR International: NVivo 8, http://www.qsrinternational .com/products previous-products nvivo8.aspx

32. Thomas, D. R.: A General Inductive Approach for Analyzing Qualitative Evaluation Data. American Journal of Evaluation. 27, 237-246 (2006)

33. The Web Content Accessibility Guidelines 1.0, http: / / Www.w3.org/TR/WCAG10/ 